\title{
The Physiologic Status of Low-Birth-Weight Infants Before and After Kangaroo Mother Care Sessions: A Retrospective Study
}

\author{
Erika Marie C. Peredo, $\mathrm{MD}^{1}$ and Maria Esterlita T. Villanueva-Uy, MD, MSPH ${ }^{1,2}$ \\ ${ }^{1}$ Institute of Pediatrics and Child Health, St. Luke's Medical Center, Quezon City \\ ${ }^{2}$ Institute of Child Health and Human Development, National Institutes of Health, University of the Philippines Manila
}

\begin{abstract}
Objective. To compare the physiologic status of infants before and after receiving kangaroo mother care (KMC) through assessment of their heart rate (HR), respiratory rate (RR), temperature, oxygen saturation, and pain scores.

Methods. We conducted a retrospective study by chart review of all low-birth weight (LBW) infants enrolled in the KMC program of a tertiary medical center. Significance is defined by lower HR, RR, PIPP score and FLACC scale, and significant increase in temperature and oxygen saturation (within normal range) after 4 hours after each KMC session.
\end{abstract}

Results. Out of the 46 LBW weight infants enrolled in the KMC program, only 23 infants had complete chart entries. A total of $99 \mathrm{KMC}$ sessions were analyzed. There was no significant difference in the HR $(p=0.331), R R(p=0.453)$, oxygen saturation ( $p=0.839)$, and PIPP $(p=0.387) / F L A C C(p=0.13)$ scores among the LBW infants before and after the $\mathrm{KMC}$ session. However, there was a significantly higher axillary temperature (within normal range) four hours after KMC ( $p=0.044)$.

Conclusions. $\mathrm{KMC}$ is associated with better thermoregulation even at four hours after the KMC session compared to four hours before. Other physiologic parameters such as heart rate, respiratory rate, oxygen saturation and pain scores were similar four hours before and after the KMC session.

Key Words: Kangaroo mother care, infant pain profile, thermoregulation, physiologic status

\section{INTRODUCTION}

Corresponding author: Erika Marie C. Peredo, MD Institute of Pediatrics and Child Health St. Luke's Medical Center, Quezon City 279 E. Rodriguez Sr. Avenue

Quezon City 1112, Metro Manila, Philippines

Email: erika_cayco_peredo@yahoo.com
Preterm complications are the top cause of neonatal mortality. ${ }^{1}$ The transition of the preterm from fetal to extrauterine life may be accompanied by a lot of stresses due respiratory distress, infection, hypothermia, and other metabolic abnormalities. Growth rates may also be suboptimal due to increased energy utilization and oxidative stress. ${ }^{2}$

Cold stress occurs in more than $90 \%$ of infants, especially those born in developing countries. Although hypothermia is rarely a direct cause of death, it contributes substantially to neonatal mortality. Preterm infants have 2.6 times the odds while no skin-to-skin contact has 3.0 times the odds of developing hypothermia. ${ }^{3}$

Kangaroo mother care (KMC) is an innovative intervention which started in Bogota Colombia, originally intended to thermoregulate infants in the absence of incubators. KMC is defined by the World Health Organization as care of preterm infants carried skin-toskin by the mother. ${ }^{4} \mathrm{KMC}$ has been shown to decrease the 
risk of hypothermia by more than $90 \% .{ }^{5}$ It has been shown to have far-reaching benefits aside from thermoregulation. In a meta-analysis done by Lawn et al., it was shown that KMC substantially reduces neonatal mortality amongst preterm babies with birth weight of less than 2000 grams. ${ }^{6}$ In a randomized controlled trial (RCT) by Gathwala et al., KMC was further shown to have a significant effect in increasing the mean weight gain, length gain, and head circumference gain in babies as compared to the control. The study also showed that KMC improved breastfeeding rates and was well accepted by mothers and the nursing staff. ${ }^{7}$ Due to all the positive effects of KMC on physical growth and reduction in mortality rate in preterm and low birth weight infants, it is now slowly being integrated in the care of the newborn in both public and private institutions in the Philippines.

$\mathrm{KMC}$ seems to calm or relax the infants. Urinary allantoin, which is a marker of oxidative stress, is lower during and after an infant receives $\mathrm{KMC}$, compared to baseline. This may translate to more optimal physiologic parameters which will lead to more energy utilized for growth and fighting infections. ${ }^{8}$

A prospective study done by Almeida, compared the $\mathrm{HR}, \mathrm{RR}$, temperature, and oxygen saturation of infants 30 minutes before, during, and 30 minutes after KMC. Results showed that there was a significant increase in the mean temperature, and oxygen saturation, and a significant decrease in the respiratory rate, 30 minutes after KMC. However, the change in heart rate was not significant before, during and after KMC. ${ }^{9}$

In an RCT by Parsa et al., there were significantly better physiologic parameters in infants during and immediately (15 minutes) after the KMC session compared with those who stayed in the incubator. ${ }^{10}$ In an observational cohort study by Jones, the duration of skin-to-skin contact did not correlate with changes in physiologic parameters. However, the oxygen requirement was noted to be more often lower across different durations of $\mathrm{KMC}$ provided. ${ }^{11} \mathrm{In}$ a crossover trial study, of 50 preterm infants in India by Chidambaram, pain infant scale scores (Premature Infant Pain Profile Scores) were significantly lower 15 and 30 minutes after heel prick in patients who received $\mathrm{KMC}$ as compared to control group. ${ }^{12}$

Most studies in the literature measured the improvement in the physiologic parameters immediately after, up to 15-30 minutes after the KMC session, it is the goal of this study to determine if the improvement, if any, of the physiologic parameters is sustained for several hours after the KMC session.

\section{OBJECTIVE}

To compare the physiologic status of term and preterm low birth weight infants four hours before and four hours after receiving $\mathrm{KMC}$.

\section{METHODS}

\section{Study Design, Population, Setting, and Duration}

We conducted a retrospective study from February to November 2014 at the Neonatal Intensive Care Unit of St. Luke's Medical Center Quezon City (SLMC QC), a tertiary medical center with a Level III NICU. It is a KMC Center of Excellence and Training where all LBW infants admitted to the NICU Level II and III units and in the maternity rooming-in units are enrolled to the KMC program.

As part of the $\mathrm{KMC}$ program, parents are approached and asked to sign a consent form which contains information about the benefits of the KMC, the conduct of the KMC in the hospital, and the intent that both mother and father come to the hospital at any time of the day to provide KMC (at least 4-6 hours/day). As per hospital protocol, vital signs are monitored every hour while the infant is receiving Level III NICU care and every four hours if the infant is admitted at the Intermediate Medical Care Unit (Level II). Infant pain scales (PIPP and FLACC) are part of the monitoring sheet and are also assessed by trained neonatal nurses at the same time as the vital signs.

\section{Inclusion criteria}

We included all LBW infants ( $<2500$ grams) enrolled to the KMC program.

\section{Exclusion Criteria}

1. Consecutive $\mathrm{KMC}$ sessions which were less than 8 hours apart since the study's observation periods would overlap

2. Incomplete physiologic parameter entries

3. Patients who underwent procedures (IV insertion, ROP screening, etc.) during the observation period

\section{Study Procedure}

We reviewed the charts of all preterm and low birth weight infants listed in the KMC enrolment logbook. We compared heart rate, respiratory rate, temperature, oxygen saturation, Face, Legs, Activity, Cry, Consolability (FLACC) Scale for full term neonates ${ }^{13}$ (Table 1), and Premature Infant Pain Profile (PIPP) Score for preterm neonates ${ }^{14}$ (Table 2), four hours before and four hours after KMC. Face, Legs, Activity, Cry, Consolability (FLACC) Scale is a scale used for quantifying and communicating preverbal pain. ${ }^{8}$ A high score is correlated with more discomfort in term infants (Table 1). The Premature Infant Pain Profile (PIPP) Score is a 7-indicator composite measure developed to assess acute pain in preterm and term neonates (Table 2). ${ }^{7}$ Pulse oximetry was continuously monitored. We planned to include the physiologic parameters during the KMC session. Other data obtained from the chart included: birthweight, gestational age at birth, weight at KMC enrolment and post-conceptional age at $\mathrm{KMC}$ enrolment. 
Table 1. Scoring system of the Face, Legs, Activity, Cry, Consolability Scale (FLACC)

\begin{tabular}{llll}
\hline \multicolumn{1}{c}{ Category } & \multicolumn{1}{c}{$\mathbf{0}$} & \multicolumn{1}{c}{$\mathbf{2}$} & \\
Face & No particular expression or smile & $\begin{array}{l}\text { Occasional grimace or frown, withdrawn, } \\
\text { disinterested }\end{array}$ & $\begin{array}{l}\text { Frequent to constant quivering } \\
\text { chin, clenched jaw }\end{array}$ \\
\hline Legs & Normal position or relaxed & Uneasy, restless, tense & Kicking or legs drawn up \\
\hline Activity & Lying quietly, normal position, moves easily & Squirming, shifting back and forth, tense & Arched, rigid or jerking \\
\hline Cry & No cry (awake or asleep) & Moans or whimpers, occasional complaint & $\begin{array}{l}\text { Crying steadily, screams or } \\
\text { sobs, frequent complaints }\end{array}$ \\
\hline Consolability & Content, relaxed & $\begin{array}{l}\text { Reassured by occasional touching, } \\
\text { hugging, or being talked to, distractible }\end{array}$ & Difficult to console or comfort \\
\hline
\end{tabular}

Table 2. Scoring system of the Premature Infant Pain Profile (PIPP)

\begin{tabular}{|c|c|c|c|c|c|}
\hline Process & Indicator & 0 & 1 & 2 & 3 \\
\hline $\begin{array}{l}\text { Score before } \\
\text { examining infant }\end{array}$ & $\begin{array}{l}\text { Corrected Gestational } \\
\text { Age (GA) }\end{array}$ & $\begin{array}{l}36 \text { completed wk. } \\
\text { or more }\end{array}$ & $\begin{array}{l}32 \text { completed wk. to } \\
356 / 7 \text { wk. }\end{array}$ & $\begin{array}{l}28 \text { completed wk. to } \\
316 / 7 \text { wk. }\end{array}$ & Less than 28 wk. \\
\hline Observe for $15 \mathrm{~s}$ & $\begin{array}{l}\text { Baseline Behavioral } \\
\text { State (BS) }\end{array}$ & $\begin{array}{l}\text { Active/awake eyes } \\
\text { open } \\
+ \text { facial movements }\end{array}$ & $\begin{array}{l}\text { Quiet/awake } \\
\text { Eyes open } \\
\text { No facial movements }\end{array}$ & $\begin{array}{l}\text { Active/sleep } \\
\text { Eyes closed } \\
+ \text { facial movements }\end{array}$ & $\begin{array}{l}\text { Quiet sleep } \\
\text { Eyes closed } \\
\text { No facial movements }\end{array}$ \\
\hline \multirow{5}{*}{$\begin{array}{l}\text { Record baseline HR } \\
\text { (max) and } \mathrm{O}_{2} \text { sat (min) } \\
\text { then observe for } 30 \mathrm{~s}\end{array}$} & Heart Rate max (HR) & $\begin{array}{l}0-4 \text { beats } / \mathrm{min} \\
\text { increase }\end{array}$ & $\begin{array}{l}5-14 \text { beats } / \mathrm{min} \\
\text { increase }\end{array}$ & $\begin{array}{l}15-24 \text { beats } / \mathrm{min} \\
\text { increase }\end{array}$ & $\begin{array}{l}>24 \text { beats } / \mathrm{min} \\
\text { increase }\end{array}$ \\
\hline & $\mathrm{O}_{2}$ sat min & $0-2 \%$ decrease & 3-4\% decrease & $5-6 \%$ decrease & $>6 \%$ decrease \\
\hline & Brow Bulge (BB) & None to $3 \mathrm{~s}$ & $>3$ to $12 \mathrm{~s}$ & $>12$ to $21 \mathrm{~s}$ & $>21$ to $30 \mathrm{~s}$ \\
\hline & Eye Squeeze (ES) & None to $3 \mathrm{~s}$ & $>3$ to $12 \mathrm{~s}$ & $>12$ to $21 \mathrm{~s}$ & $>21$ to $30 \mathrm{~s}$ \\
\hline & Nasolabial Furrow (NF) & None to $3 \mathrm{~s}$ & $>3$ to $12 \mathrm{~s}$ & $>12$ to $21 \mathrm{~s}$ & $>21$ to $30 \mathrm{~s}$ \\
\hline
\end{tabular}

Score of 0-6 No action

Score of 7-12 Non-pharmacological intervention (e.g., Positioning, containment, swaddling, Non-nutritive sucking)

Score of $>12$ Pharmacological Intervention (e.g., Narcotics) Re-assess in 15-30 minutes for effectiveness of intervention

\section{Ethical considerations}

The study protocol was approved by the Institutional Scientific Research Committee (ISRC) and Institutional Ethics Review Committee (IERC) of St. Luke's Medical Center-Quezon City. Because the data was extracted retrospectively, and no interventions were performed, informed consent was not required.

\section{Data Analysis}

The unit of analysis were the KMC sessions recorded in the monitoring sheets. Data were encoded in Microsoft Excel. XLStat for Microsoft Excel was used for analysis. Mean and standard deviations were computed for continuous data. T-test was utilized to compare the means of the HR, $\mathrm{RR}$, temperature, oxygen saturation, FLACC and PIPP scores, taken four hours before and four hours after the $\mathrm{KMC}$ session. The level of significance was set at $<0.05$.

\section{RESULTS}

Of the 46 infants enrolled in the KMC program during the study period, only 23 infants had complete entries. However, these were usually incomplete entries since the mother/father-infant dyads were allowed privacy with the infant on pulse oximetry so that the temperature and the respiratory rates were not measured. Furthermore, the pain scales would require observation of movement of extremities and facial expressions which would be intrusive during the parent-infant bonding.

Among the 23 LBW patients included in the study, all were preterm except for one patient who was born term small-for-gestational age. The mean gestational age was $31.52 \pm 2.97$ weeks with mean birthweight of $1615 \pm 464.4$ g. On enrolment, the mean post-conceptional age was 32.7 \pm 2.13 weeks and a weight of $1696.2 \pm 405.55$ grams. The $\mathrm{KMC}$ sessions ranged from 1 to 15 hours per day with a mean duration of $4.3 \pm 3.6$ hours per day (Table 3 ).

A total of $99 \mathrm{KMC}$ sessions were analyzed. The physiologic parameters noted four hours before and four hours after the KMC session such as the heart rate (149.6 vs 149),

Table 3. Baseline characteristics of study population

\begin{tabular}{lrr}
\multicolumn{1}{c}{ Variable } & Mean & \multicolumn{1}{c}{ SD } \\
\hline Age of gestation (wks.) & 31.5 & 2.97 \\
\hline Post-conceptional age on Enrolment to LMC (wks.) & 32.7 & 2.13 \\
\hline Birthweight (g) & 1615.4 & 464.40 \\
\hline Weight on Enrolment (g) & 1696.2 & 2.13 \\
\hline Duration of KMC sessions (hours) & 4.3 & 3.60 \\
\hline
\end{tabular}


KMC in Low-Birth-Weight Infants

Table 4. Comparison of physiologic parameters rate 4 hours before and 4 hours after KMC session

\begin{tabular}{|c|c|c|c|c|c|c|}
\hline \multirow{2}{*}{ Variable } & \multirow{2}{*}{$\begin{array}{c}\text { No. of } \\
\text { observations }\end{array}$} & \multicolumn{2}{|c|}{ Before KMC } & \multicolumn{2}{|c|}{ After KMC } & \multirow{2}{*}{ P value } \\
\hline & & Mean & SD & Mean & SD & \\
\hline Heart Rate & 98 & 149.6 & 8.5 & 149.0 & 9.6 & 0.331 \\
\hline Respiratory Rate & 99 & 49.8 & 4.93 & 49.7 & 5.17 & 0.453 \\
\hline Temperature & 98 & 36.6 & 0.15 & 36.7 & 0.131 & 0.044 \\
\hline Oxygen saturation & 67 & 98.5 & 1.493 & 98.2 & 1.763 & 0.839 \\
\hline PIPP & 24 & 3.2 & 0.3 & 3.2 & 0.3 & 0.387 \\
\hline FLACC & 6 & 1.5 & 0.5 & 1.5 & 0.4 & 0.130 \\
\hline
\end{tabular}

respiratory rate (49.8 vs 49.7 ) and oxygen saturations (98.6 vs 98.2) were similar. It was only the axillary temperature which was significantly higher after the KMC session (36.6 vs 36.7 C) ( $\mathrm{p}=0.044)$ (Table 4). The lower value in the range of temperature measured four hours prior to the $\mathrm{KMC}$ session (range: $36.0-37.1{ }^{\circ} \mathrm{C}$ ) was hypothermic compared with the temperature range reported four hours after the $\mathrm{KMC}$ session (range: $36.5-37.1^{\circ} \mathrm{C}$ ), which were within normal temperature range.

For the pain scales, the PIPP and the FLACC scores were identical four hours before and four hours after the KMC session (Table 4).

\section{DISCUSSION}

Our findings revealed that there was no significant difference in the HR, RR, oxygen saturation four hours before and four hours after $\mathrm{KMC}$ sessions. In a prospective study done by Almeida, et al., there were significant improvements in the respiratory rate and the oxygen saturation after the KMC sessions. ${ }^{3}$ Similarly, a quasi-experimental study by Parsa also showed better physiologic parameters (HR, RR, temperature, oxygen saturations) after the KMC session. The difference in outcomes between this study and those of Almeida and Parsa could be due to the difference in the length of the observation period before and after KMC. Almeida and Parsa had shorter observation periods. In Almeida's study, monitoring was 30 minutes before and 30 minutes after KMC while in Parsa's study, the observation was 15 minutes before and immediately after the KMC sessions. In our study, the observation period was four hours before and four hours after the $\mathrm{KMC}$ sessions. The longer observation period employed in this study was to determine sustained and persistent improvement in physiologic parameters after $\mathrm{KMC}$. As can be noted, there were improvement in physiologic parameters like HR, RR, and oxygen saturations up to 30 minutes after the $\mathrm{KMC}$ session in the aforementioned studies, but this was not noted four hours after.

Thermoregulation in preterm and LBW infants is difficult to maintain due to a multitude of factors, such as the immaturity of their nerve centers, the scarcity of subcutaneous cellular tissue and the oxygen offer, which is limited by respiratory disorders. This was the main reason why its proponents initiated KMC in the 1970s in Colombia. ${ }^{14}$ In this study, there is a sustained effect of $\mathrm{KMC}$ on thermoregulation even at four hours after the KMC session. The difference in the mean temperature before and after the $\mathrm{KMC}$ session $\left(36.6\right.$ vs $36.7^{\circ} \mathrm{C}$ ) was statistically significant but may be deemed not clinically pertinent. However, on reviewing the temperature ranges, the lower value of the temperature range prior to the $\mathrm{KMC}\left(36.0-37.1{ }^{\circ} \mathrm{C}\right)$ was below normal compared with the temperature range after $\mathrm{KMC}$, which were all within normal values $\left(36.5-37.1^{\circ} \mathrm{C}\right)$. This finding of sustained thermoregulation in this study implies a prolonged beneficial effect of the KMC among these high-risk infants.

Infants admitted in the neonatal intensive care unit experience pain due to various procedures performed. In a randomized controlled trial study by Pandita, the infants on KMC versus swaddling had neonatal infant pain scale (NIPS) which were lower at 1 and 5 minutes after vaccination. ${ }^{15}$ Similarly, a randomized controlled trial by Shukla, using the PIPP scale, showed lower pain scores among preterm infants on $\mathrm{KMC}$ who underwent heel prick. ${ }^{16}$ Chidambaram also compared the mean PIPP scores of infants undergoing heel prick whether on KMC or not. The PIPP scores were lower 15 minutes and 30 minutes after the heel prick. ${ }^{11}$ In this study, the two pain scales (FLACC, and PIPP) were identical four hours before and four hours after the KMC session. This may be because any painful procedures performed during the observation period in this study were excluded. Still, the infants could have experienced continuous environmental disturbances, which may be in the form of noise (e.g., IV pumps, ventilators) and handling for routine care. The lower number of KMC sessions with recorded PIPP and FLACC scores may have also affected the results. There were only 6 sessions of $\mathrm{KMC}$ with recorded FLACC scores and 24 sessions with PIPP scores.

This study showed that KMC may have a prolonged beneficial effect on thermoregulation among LBW infants even at four hours after the KMC session. Improvement in physiologic parameters like $\mathrm{HR}, \mathrm{RR}$, oxygen saturation and pain scale scores after KMC may not be sustained for a long time. This emphasizes the need to provide longer KMC sessions as other studies have shown benefits of 
$\mathrm{KMC}$ on physiologic parameters during and immediately after the KMC session. As such, to be able to obtain the full benefits of $\mathrm{KMC}$, longer $\mathrm{KMC}$ sessions (intermittent $\mathrm{KMC}>8$ hours/day and continuous $\mathrm{KMC}>18$ hours/day) should be recommended.

\section{CONCLUSION}

There is evidence to show that thermoregulation is sustained among LBW infants at four hours after the KMC session. Other physiologic parameters like HR, RR and oxygen saturations and pain scales were similar four hours before and four hours after the KMC session. Limitations of this study are its retrospective design and the small population included.

\section{Recommendations}

Prospective cohort studies should be undertaken which would be able to assess the physiologic parameters continuously for longer periods to be able to determine the duration of KMC benefit among the preterm and LBW infants. Prolonged continuous monitoring will also be able to identify events in the NICU that are stressful to the infants based on changes on the physiologic parameters and pain scales. Moreover, a bigger study population should be included in future $\mathrm{KMC}$ research.

\section{Statement of Authorship}

Both authors participated in the data collection and analysis and approved the final version submitted.

\section{Author Disclosure}

Both authors declared no conflicts of interest.

\section{Funding Source}

This study has no funding source.

\section{REFERENCES}

1. GBD 2016 Causes of Death Collaborators. Global, regional, and national age-sexspecific mortality for 264 causes of death, 1980-2016: a systematic analysis for theGlobal Burden of Disease Study 2016. Lancet. 2017 Sep 16; 390(10100):1151-1210. doi: 10.1016/S01406736(17)32152-9. Erratum in: Lancet. 2017 Oct28;390(10106): e38.

2. Macedo I, Pereira-da-Silva L, Cardoso M. Associations of measured protein andenergy intakes with growth and adiposity in human milkfed preterm infants atterm postmenstrual age: a cohort study. Am J Perinatol. 2018 Jul; 35(9):882-91. doi: 10.1055/s-0038-1626717.
3. Yitbalti YA, Aitaye EB, Lechissa HW, Gebeyehu LO. Neonatal hypothermia andassociated factors among newborns admitted in the neonatal intensive care unitof Dessie Referral Hospital, Amhara Region, Northeast Ethiopia. Int J Pediatr.2020 Sep 14; 2020:3013427. doi: $10.1155 / 2020 / 3013427$.

4. World Health Organization. Kangaroo Mother Care: A Practical Guide. Geneva, Switzerland: World Health Organization, Department of Reproductive Health and Research; 2003

5. Ibe OE, Austin T, Sullivan K, Fabanwo O, Disu E, Costello AM. A comparison ofkangaroo mother care and conventional incubator care for thermal regulation ofinfants $<2000 \mathrm{~g}$ in Nigeria using continuous ambulatory temperature monitoring.Ann Trop Paediatr. 2004 Sep; 24(3):245-51. doi: 10.1179/027249304225019082.

6. Lawn JE, Kinney M, Mwansa-Kambafwile J, Horta BL, Barros FC, Cousens S.'Kangaroo Mother Care' to prevent neonatal deaths due to preterm birthcomplications. Int J Epidemiol. 2010; i1-i10. doi: 10.1093/ije/dyq044

7. Gathwala G, Singh B, Singh J. Effect of Kangaroo mother care on physical growth,breastfeeding and its acceptability. Trop Doct. 2010; 40(4):199-202

8. Forde D, Deming DD, Tan JC, Phillips RM, Fry-Bowers EK, Barger $\mathrm{MK}$, et al. Oxidativestress biomarker decreased in preterm neonates treated with kangaroo mothercare. Biol Res Nurs. 2020 Apr;22(2): 188-196. doi: 10.1177/1099800419900231.

9. Almeida, CM, Almeida, AFN, \& Forti, EMP. Effects of Kangaroo Mother Care on the vital signs of low-weight preterm newborns. Brazilian Journal of Physical Therapy.2007; 11(1):1-5.

10. Parsa P, Karimi S, Basiri B, Roshanaei G. The effect of kangaroo mother care onphysiological parameters of premature infants in Hamadan City, Iran. Pan Afr MedJ. 2018 May 31; 30:89. doi: 10.11604/ pamj.2018.30.89.14428.

11. Jones H, Santamaria N. An observational cohort study examining the effect of the duration of skin-to-skin contact on the physiological parameters of the neonate ina neonatal intensive special care unit. Adv Neonatal Care. 2018 Jun; 18(3):208-14. doi: 10.1097/ ANC. 0000000000000485 .

12. Chidambaram AG, Manjula S, Adhisivam B, Bhat BV. (2013). Effect of Kangaroo mother care in reducing pain due to heel prick among preterm neonates: a crossover trial. J Matern Fetal Neonatal Med. 2014 Mar; 27(5):488-90. doi: 10.3109/14767058.2013.818974.

13. Manworren R, Hynan L, Clinical Validation of FLACC: Preverbal Patient Pain Scale. Pediatric Nursing. 2003; 29(2)

14. Stevens B, Johnston C, Petryshen P, Taddio A. (1996). Premature infant pain profile: Development and initial validation. Clinical Journal of Pain, 12 (1): 13-22.

15. Pandita A, Panghal A, Gupta G, Verma A, Pillai A, Singh A, Naranje K. Is kangaroo mother care effective in alleviating vaccination associated pain in early infantile period? A RCT. Early Hum Dev. 2018 Dec; 127:69-73. doi: 10.1016/j.earlhumdev.2018.10.001.

16. Shukla VV, Bansal S, Nimbalkar A, Chapla A, Phatak A, Patel D, et al. Pain control interventions in preterm neonates: a randomized controlled trial. Indian Pediatr. 2018 Apr 15; 55(4):292-6. 